Article

\title{
Final Destination? Pinpointing Hyella disjuncta sp. nov. PCC 6712 (Cyanobacteria) Based on Taxonomic Aspects, Multicellularity, Nitrogen Fixation and Biosynthetic Gene Clusters
}

\author{
Patrick Jung ${ }^{1, *,+}\left(\mathbb{D}\right.$, Paul M. D'Agostino ${ }^{2,+}\left(\mathbb{D}\right.$, Katharina Brust ${ }^{3}$, Burkhard Büdel ${ }^{4}$ and Michael Lakatos ${ }^{1}$ (D) \\ 1 Department of Integrative Biotechnology, University of Applied Sciences Kaiserslautern, \\ Carl-Schurz-Str. 10-16, 66953 Pirmasens, Germany; michael.lakatos@hs-kl.de \\ 2 Department of Technical Biochemistry, Technical University of Dresden, Bergstr. 66, 01069 Dresden, Germany; \\ paul.dagostino@tu-dresden.de \\ 3 Department of Ecology, University of Kaiserslautern, Erwin Schrödinger Str. 14, \\ 67663 Kaiserslautern, Germany; katharina.brust@web.de \\ 4 Department of Plant Ecology and Systematics, University of Kaiserslautern, Erwin-Schrödinger Str. 52, \\ 67663 Kaiserslautern, Germany; buedel@bio.uni-kl.de \\ * Correspondence: patrick_jung90@web.de; Tel.: +49-15165105161 \\ + Both authors contributed equally to this article.
}

\section{check for} updates

Citation: Jung, P.; D'Agostino, P.M.; Brust, K.; Büdel, B.; Lakatos, M. Final Destination? Pinpointing Hyella disjuncta sp. nov. PCC 6712 (Cyanobacteria) Based on Taxonomic Aspects, Multicellularity, Nitrogen Fixation and Biosynthetic Gene Clusters. Life 2021, 11, 916. https:// doi.org/10.3390/life11090916

Academic Editor: Christopher H. House

Received: 27 July 2021

Accepted: 30 August 2021

Published: 3 September 2021

Publisher's Note: MDPI stays neutral with regard to jurisdictional claims in published maps and institutional affiliations.

Copyright: (C) 2021 by the authors. Licensee MDPI, Basel, Switzerland. This article is an open access article distributed under the terms and conditions of the Creative Commons Attribution (CC BY) license (https:/ / creativecommons.org/licenses/by/ $4.0 /)$.

\begin{abstract}
Unicellular cyanobacteria inhabit a wide range of ecosytems and can be found throughout the phylum offering space for taxonomic confusion. One example is strain PCC 6712 that was described as Chlorogloea sp. (Nostocales) and later assigned to the genus Chroococcidiopsis (Chroococcidiopsidales). We now show that this strain belongs to the order Pleurocapsales and term it Hyella disjuncta based on morphology, genome analyses and 16S-23S ITS rRNA phylogeny. Genomic analysis indicated that $H$. disjuncta PCC 6712 shared about $44.7 \%$ orthologue genes with its closest relative $H$. patelloides. Furthermore, 12 cryptic biosynthetic gene clusters (BGCs) with potential bioactivity, such as a mycosporine-like amino acid BGC, were detected. Interestingly, the full set of nitrogen fixation genes was found in $H$. disjuncta PCC 6712 despite its inability to grow on nitrogenfree medium. A comparison of genes responsible for multicellularity was performed, indicating that most of these genes were present and related to those found in other cyanobacterial orders. This is in contrast to the formation of pseudofilaments-a main feature of the genus Hyella — which is weakly expressed in H. disjuncta PCC 6712 but prominent in Hyella patelloides LEGE 07179. Thus, our study pinpoints crucial but hidden aspects of polyphasic cyanobacterial taxonomy.
\end{abstract}

Keywords: Pleurocapsales; genomics; biosynthetic gene cluster; Chroococcidiopsis; Hyella

\section{Introduction}

Pleurocapsalean cyanobacteria represent a phylogenetically well-framed group (see, e.g., [1,2]) but are still poorly investigated on several levels. Most are unicellular and marked by the formation of baeocytes or pseudofilaments. The problem is that a large number of genera in this order lack sequence data and are very difficult to transfer in pure cultures [1]. Although the order is highly diverse and species rich, only a few genera have been studied to an extent where a highly accurate taxonomic placement based on modern standards has been achieved. This is the case for the genus Pleurocapsa, for which in 2019 the neotype and epitype for P. minor and P. fuliginosa were finally introduced [3]. In order to further strengthen taxonomy within the Pleurocapsales, additional strains need to be revised whose classification were based primarily on morphology, and therefore, they may be incorrect.

Several names given to species in the order Chroococcidiopsidales such as Gloeocapsopsis pleurocapsoides still indicate the difficulties discriminating members of the 
two orders Chroococcidiopsidales and Pleurocapsales based on morphology, although their 16S rRNA-based phylogeny clearly separates both orders [4]. The most prominent case highlighting this issue is the cyanobacterial strain PCC 6712 that was isolated in 1967 by R. Kunisawa from a freshwater reservoir in Marin County, California and originally reported as Chlorogloea sp. (Nostocales) by Kenyon in 1972 [5]. Later, DNA of the strain PCC 6712 was partially sequenced and phylogenetically compared resulting in a reclassification of the strain as Chroococcidiopsis sp. (Chroococcidiopsidales) by Waterbury [6]. This decision was also supported by findings of non-motile baeocytes in strain PCC 6712, a clear indicator at that time for this isolate belonged to the order Chroococcidiopsidales because most baeocytous Pleurocapsales have motile baeocytes [7]. However, simultaneously, the authors noticed significant differences between PCC 6712 and other members of the genus Chroococcidiopsis. From then on, several studies covering broad scientific fields used this strain, always referring to it as 'Chroococcidiopsis sp.' PCC 6712, but at the same time, again, reporting striking differences between this strain and other Chroococcidiopsis species. This includes early studies on comparative cyanobacterial analyses [8], secondary metabolites [9], fatty acid composition [10], phylogenetic and morphological investigations [4], functional genomics [11], salt tolerance [12] and testing cell counting algorithms [13].

The isolate 'Chroococcidiopsis sp.' PCC 6712 was also a major focus with respect to novel natural products [14] enabled by the release of the full genome by [15]. Brito et al. [14] showed a direct phylogenetic relation between 'Chroococcidiopsis sp.' PCC 6712 and Hyella patelloides LEGE 07179 on a genome level, and a previous study by Brito et al., in 2017 [16], also indicated that the strain is Pleurocapsalean based on 16S phylogeny and might be an additional species of the genus Hyella. Interestingly, a discrepancy appeared behind this idea because a main feature of the genus Hyella is the prominent formation of pseudofilaments, a characteristic that is well present in H. patelloides LEGE 07179 but was not described previously for strain PCC 6712 [6,7,17-19].

In the present article, we resolve this situation and apply a full taxonomic investigation including the polyphasic approach as the standard in cyanobacterial taxonomy. This is based on morphological investigations of the strain Chroococcidiopsis sp. PCC 6712, including various media and substrates as well as sequencing and phylogenetic analysis of the 16S-23S rRNA. Taxonomic and morphological data obtained in this study are further supported by a greater in-depth analysis of the genome with a focus on multicellularity, nitrogen fixation and the presence of natural product biosynthetic gene clusters (BGCs). Overall, we here present the reassignment of Chroococcidiopsis sp. PCC 6712 to the new Hyella species Hyella disjuncta PCC 6712.

\section{Materials and Methods}

\subsection{Origin of Strain and Culture Conditions}

The investigated strain was isolated in 1967 by R. Kunisawa from a freshwater reservoir, Marin County, California and originally reported as Chlorogloea sp. [5,7,20]. Later on, the strain was re-classified as Chroococcidiopsis, but at the same time, the authors noticed significant differences between strain PCC 6712 and other Chroococcidiopsis isolates [6].

In our laboratory, the strain was kept in liquid BG11 medium [20] as well as on agar plates in a culture cabinet (CLF Plantclimatics, Percival, Wertingen, Germany) at photosynthetic photon flux density of $30 \mu \mathrm{mol} \mathrm{m} \mathrm{m}^{-2} \mathrm{~s}^{-1}, 20^{\circ} \mathrm{C}$ and a light:dark cycle of 16:8 $\mathrm{h}$. The strain was also cultured under the same conditions in 6 well plates filled with $5 \mathrm{~g}$ sterilized quartz sand and basalt grains, to which we added $2 \mathrm{~mL}$ liquid BG11 medium twice a week to stimulate growth on lithic substrates, known as a preference from other Hyella species [16]. Additionally, other liquid media were used such as NM (seawater base supplemented with the minerals of medium BG11 at half strength) [21] that were used in previous studies for, e.g., H. patelloides LEGE 07179 [16], in order to enhance comparability of, e.g., morphology. Additionally, nitrogen-free BG11 medium was tested to check for the nitrogen fixing ability of the strain on which growth was monitored over the course of three months. 
Motility of, e.g., baeocytes acts as a discrimination feature between unicellular pleurocapsalean and chroococcidiopsidalean taxa [7]. Thus, a motility test was applied by transferring small proportions of the culture on one side of agar plates with BG11 medium. This side of the plate was fully covered with black adhesive tape and placed in a culture cabinet as described above in a way that the uncovered side was directed orthogonally to the light source. Once a week over the course of three months it was checked regularly by means of light microscopy if the cells were motile at any stage of their developmental cycles and moved towards the light.

\subsection{Morphological Characterization}

The morphology of strain PCC 6712 was checked weekly over the course of several months growing in liquid BG11 and NM medium, on BG11 agar plates, on quartz sand and basalt grains by light microscopy using a Panthera KU Trinocular (Motic, Barcelona, Spain) equipped with $10 \times, 20 \times, 40 \times$ and $100 \times$ magnification, oil immersion and an Auramine $\mathrm{O}$ fluorescence module $(455 \mathrm{~nm})$ coupled with a MicroLive Multi Format camera (Lifesolution, Bremen, Germany) and the software MicroLive (v4.0). In addition, differential interference contrast (DIC) images were taken with an Axisokop (Carl Zeiss, Jena, Germany). Fifty images were taken from the strain and the length and widths of the cells were measured for 50 cells with MicroLive (v4.0). To visualize the sheath material of the cells ACN staining was used (20:1:1 mix; $0.1 \mathrm{~g}$ Astrablue in $79.5 \mathrm{~mL} \mathrm{H}_{2} \mathrm{O}$ and $2.5 \mathrm{~mL}$ acetic acid; $0.1 \mathrm{~g}$ Chysoidine in $100 \mathrm{~mL} \mathrm{H}_{2} \mathrm{O}$; $0.1 \mathrm{~g}$ Neufuchsin in $100 \mathrm{~mL} \mathrm{H}_{2} \mathrm{O}$; Carl Roth, Karlsruhe, Germany) that allows a differentiation of structures after colors due to the binding characteristics of the substances. Acid mucopolysaccharides are stained blue by Astrablue, cellulose or lignin are stained red by Neufuchsin and hydrophobic substances, such as Cutin, are stained yellow.

\subsection{Molecular Characterization}

The 16S-23S ITS gene region of the strain was sequenced by us to ensure its authenticity after the following workflow. Roughly $20 \mathrm{mg}$ of three weeks old culture material was scraped off agar plates and collected in $1.5 \mathrm{~mL}$ tubes with $300 \mu \mathrm{L}$ SoluLyse, a lysis buffer for protein extraction of bacteria (Amsbio, Abingdon, England). Samples were crushed manually with potter sticks and incubated over night at room temperature on a shaking plate at 110 rpm (Unimax 1010; Heidolph Instruments, Kehlheim, Germany). Afterward, $300 \mu \mathrm{L}$ of Buffer B (1.4 M NaCl, $20 \mathrm{mM}$ EDTA-Na2, $100 \mathrm{mM}$ Tris-HCl, $\mathrm{pH}$ 8.6) were added and vortexed for a few seconds. DNA was purified by adding $500 \mu \mathrm{L}$ chloroform:isoamyl alcohol (24:1), shaking for $5 \mathrm{~min}$ and centrifuging for $5 \mathrm{~min}$ at $11,000 \times \mathrm{g}$. The resulting upper phase was transferred to a new $1.5 \mathrm{~mL}$ tube and $500 \mu \mathrm{L}$ of phenol:chlorophorm (1:1) was added. After shaking and centrifuging, the chloroform/isoamyl step was repeated and the supernatant again collected to which $1 / 10(v / v)$ sodium acetate and 2/3 $(v / v)$ of isopropanol were added in order to precipitate the extracted genomic DNA in the freezer overnight. Finally, a DNA pellet was obtained by spinning the DNA down at $14,000 \times g$ for $20 \mathrm{~min}$, which was washed with $500 \mathrm{~mL}$ pre-chilled ethanol (70\%) and resuspended in $100 \mu \mathrm{L}$ ddH2O.

The 16S-23S ITS gene region was amplified by PCR in a $50 \mu \mathrm{L}$ reaction using the primers Wil1 and Wil18 [22] and ready-to-go PCR mini beads (GE Healthcare, Chicago, IL, USA) in a miniAmp thermocycler (Thermo Fisher, Waltham, MA, USA) under the conditions described in [22]. The quality of the PCR products was checked by means of agarose gel electrophoresis using $1 \%(w / v)$ agarose and subsequently purified with the NucleSpin Gel and PCR Clean-up Kit (Macherey-Nagel, Düren, Germany) following the DNA and PCR clean-up protocol. Purified PCR products were sent for Sanger sequencing to Genewiz (Leipzig, Germany) using primers Wil1, Wil4, Wil5, Wil10, Wil11, Wil16 and Wil18.

The generated sequences were assembled with Geneious Prime (v2021.0.1) software package (Biomatters Limited, Auckland, New Zealand) and compared to the genome of the strain that was already generated and deposited by others at NCBI. 
The assembled 16S rRNA gene sequences obtained from the isolate and related sequences of cyanobacterial strains cited from GenBank were used for phylogenetic analyses including Gloeobacter, representing one of the evolutionary oldest cyanobacterial taxa as an outgroup for the 16S rRNA alignment applying the Muscle algorithm in Mega X v10.2.4 [23].

Finally, 100 nucleotide sequences were used for the phylogenetic comparison, including $1466 \mathrm{bp}$ of the 16S rRNA gene. Ambiguous regions within the alignments were adjusted or removed manually, allowing smaller final blocks and gap positions within the final blocks. The evolutionary model that was best suited to the used database was selected on the basis of the lowest AIC value (Akaike Information Criterion) and calculated in Mega X. The phylogenetic tree was finally constructed with Mega X using the evolutionary Kimura 2 Parameter Model+G+I of nucleotide substitutions. The maximum likelihood method (ML) with 1000 bootstrap replications was calculated with Mega X and Bayesian phylogenetic analyses with two runs of eight Markov chains were executed for one million generations with default parameters with Mr. Bayes 3.2.1 [24]. The analysis reached stationarity (average standard deviation of split frequencies between runs $<0.01$ ) well before the end of the run. Finally, the phylogenetic tree was recalculated with NGPhylogeny.fr [25] and displayed and edited with iTOL v6.3 [26].

Models of the secondary structure of 16S-23S ITS region of all isolates were built in comparison to phylogenetic or morphologically related genera. Helices were folded with the online software RNAstructure Web Server [27].

\subsection{Holotype Preparation}

The new species was described following the rules and requirements of the International Code of Nomenclature for algae, fungi and plants [28]. For the preservation of the type strain a young, 3-week-old culture was transferred into a $5 \mathrm{~mL}$ glass bottle with a $4 \%(v / v)$ formaldehyde-water mixture. Preserved material is deposited in the Herbarium Hamburgense, Hamburg, Germany (HBG-025124) while living culture material is available via several public culture collections (PCC 6712, ATCC 27176, CCAP 1411/2).

\subsection{Bioinformatic Analysis}

The genomes of the following organisms were downloaded from NCBI and visualized using the Geneious software package (Version 8.1.9, Geneious, Auckland, New Zealand). All genome comparisons were performed against a database of selected genomes representing the Pleurocapsales (NCBI:txid52604) and Chroococcidiopsis thermalis PCC 7203 (CP003597), while other genomes were included as a reference for each specific analysis as described below.

The selected database of genomes include: Hyella disjuncta PCC 6712 (formerly Chroococcidiopsis sp. PCC 6712, ANCI00000000); H. patelloides LEGE 07179, NZ_LR213766; C. thermalis PCC 7203, CP003597; Myxosarcina sp. GI1, NZ_JRFE00000000; Pleurocapsa sp. PCC 7327 (representative of Pleurocapsa sp.), NC_019689; Pleurocapsales cyanobacterium LEGE 10410 (representative of Pleurocapsales cyanobacterium), JADEXJ000000000; Stanieria cyanosphaera PCC 7437, CP003653; Stanieria sp. NIES-3757, AP017375 and Xenococcus sp. PCC 7305, ALVZ00000000. While Hyellaceae cyanobacterium CSU_1_1 and Hydrococcus rivularis NIES-593 are classified as Pleurocapsales, they were not included in the analysis due to incomplete data describing their correct taxonomic position. Creation of the genome sequence database, gene cluster alignments and gene cluster figures were generated using the cblaster (Version 1.3.8, Massachusetts Institute of Technology, Cambridge, MA, USA) and clinker (Version 0.0.21, Massachusetts Institute of Technology, Cambridge, MA, USA) bioinformatic tools $[29,30]$. Default cblaster and clinker settings were used unless otherwise specified. 


\subsection{Genes Involved in Multicellularity}

A list of genes proposed to be involved in multicellularity were first obtained from [31,32], followed by a literature search to include additional genes. For the comparison, we only chose 18 genes with a known function or role involved in multicellularity and the locus_tag of each gene from Nostoc sp. PCC 7120 is used as reference. The final list of searched multicellular genes included the fra cluster sepJ (fraG; alr2338), fraE (alr2394), fraC (alr2392), fraD (alr2393) and fraH (alr1603) [33-38]; the amiC operon genes amiC1 (alr0092), amiC2 (alr0093) and murI (alr0094) [39-41]; the mur operon murB (alr5066) and murC (alr5065) [42]; mreB (all0087), mreC (all0086), mreD (all0085) [43], $m d r A ~(a l r 5045)$ and alr2270 [44]; cydiv (all2320) [45]; and hetR (alr2339), patU3 (alr0101) and hetZ (alr0099) [46]. Multicellularity genes listed in Figure 1 were screened using the BLASTp algorithm and each respective gene from Nostoc sp. PCC 7120 was used as a query sequence. To be included as a homologue, each gene hit needed to have at least $80 \%$ sequence coverage to the query sequence. For alignment of the ami gene cluster, BLASTp hits of amiC1 were used to identify the ami operon in each respective genome. The operon was extracted as a genbank sequence and aligned using the clinker tool and with an identity setting $(-i)$ of 0.3 . Additional genomes involved in multicellularity analysis include: Fischerella sp. PCC 9339, ALVS00000000; Gloeocapsopsis dulcis AAB1 (formerly Gloeocapsopsis sp. AAB1 = 1H9; [47]), NAPY00000000; Gloeocapsa sp. PCC 7428, NC_019745; Nostoc punctiforme PCC 73102, CP001037; Nostoc sp. PCC 7120, NC_003272; Synechococcus elongatus PCC 6301, NC_006576; and Synechocystis sp. PCC 6308, CM001775.

\subsection{Genes Involved in Nitrogen Fixation}

Reference nif gene clusters were obtained from Thiel et al. [48]. Additional genomes for analysis of nitrogen fixation include: Crocosphaera subtropica ATCC 51142, NZ_AGJC02000001; Leptolyngbya boryana dg5, NZ_AP014642; Trichormus variabilis ATCC 29413 (formerly Anabaena variabilis ATCC 29413), NC_007413 and Nostoc sp. PCC 7120, NC_003272. The nifB gene (based on its essential role in nitrogenase assembly [49]) was searched in all relevant genomes and the cluster extracted as a genbank file. The relevant genbank files were then aligned using clinker and an identity setting $(-i)$ of 0.3 .

\subsection{The mys Biosynthetic Gene Cluster}

The mycosporine-like amino acids (MAAs) encoded by the mys BGC were identified within Hyella disjuncta PCC 6712 using the identified locus_tag described in D'Agostino et al. [50]. The entire proposed mys operon was used as a query sequence and using cblaster to screen against all available Pleurocasaples genomes in addition to the two mys reference genomes of N. punctiforme PCC 73102 [51] and Trichormus variabilis ATCC 29413 (formerly Anabaena variabilis ATCC 29413) [52]. Each operon was extracted as a genbank sequence and aligned using the clinker tool and an identity setting $(-i)$ of 0.3 .

\subsection{Genome Mining for Biosynthetic Gene Clusters and Potential Antibiotic Production}

The genomes of H. disjuncta PCC 6712 and H. patelloides LEGE 07179 were submitted to AntiSMASH (Version 6.0, University of Tübingen, Tübingen, Germany) [53] with relaxed settings and all extra features turned on to identify predicted biosynthetic gene clusters (BGCs). The search for possible antibiotic resistance mechanisms and gene duplications was done using the Antibiotic Resistant Target Seeker (ARTS; Version 2.0, https:/ /arts. ziemertlab.com/ accessed on 25 July 2021) [54] with all options turned on. 


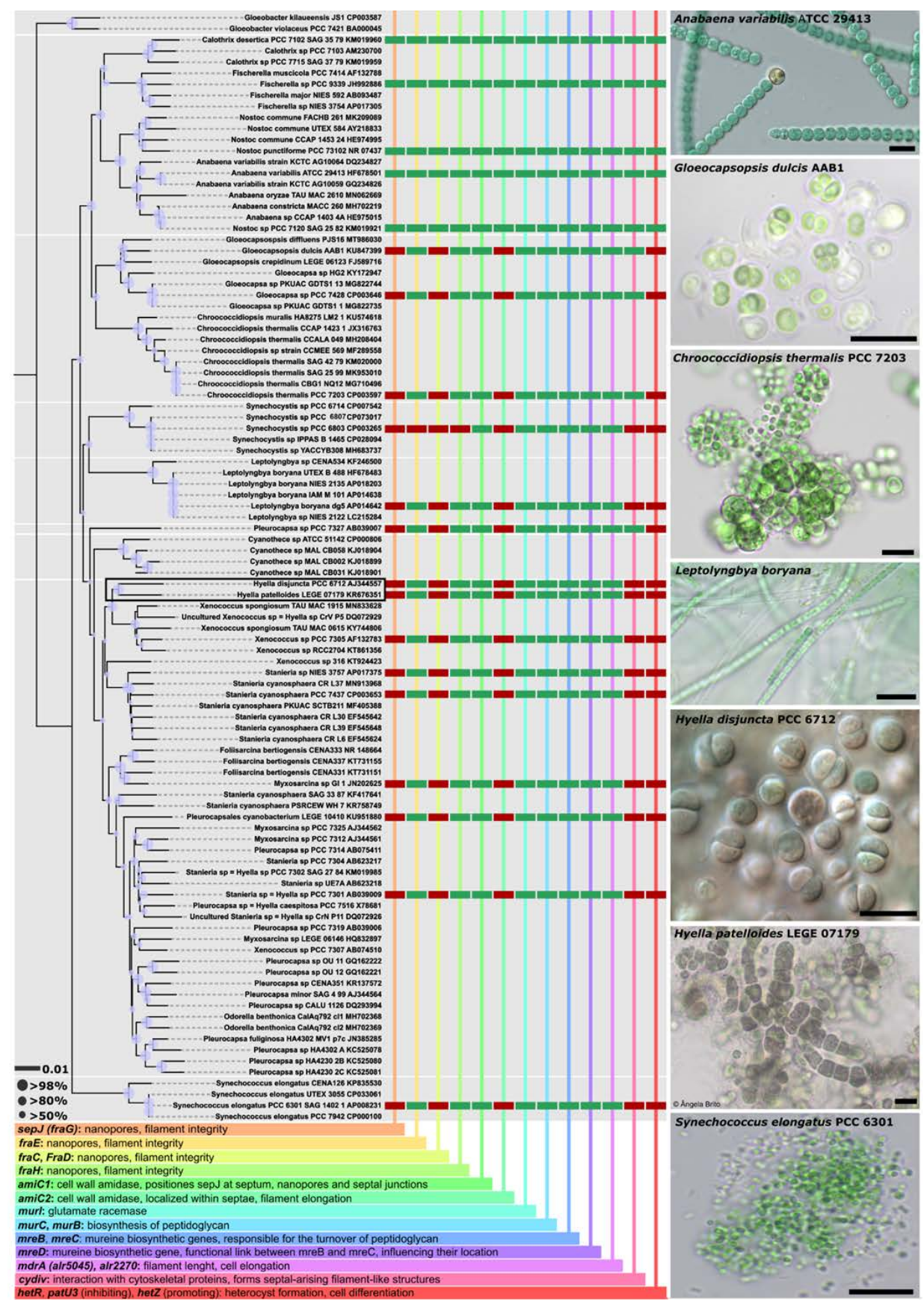

Figure 1. Maximum Likelihood (ML) phylogenetic tree based on the 16S rRNA, overview of genes involved in multicellularity and heterocyte formation and micrographs. The ML phylogenetic tree indicates the position of Hyella disjuncta sp. nov. PCC 6712 involving 100 16S rRNA sequences (1466 bp) rooted to Gloeobacter. For each sequence, the strain number as well as the NCBI GenBank accession number is displayed. Taxonomic names marked with $=$ were suggested by [3]. Since the resulting Bayesian and ML phylogenetic trees mostly showed the same topology, a single tree with both Bayesian and ML bootstrap values is shown. Statistic support at the nodes (Bayesian inference/Maximum Likelihood) represents posterior probabilities and bootstrap values indicated as circles of different sizes referring to percent intervals. The scale bar specifies 0.01 expected changes per site. The colored chart displays the presence (green)/absence (red) of genes involved in multicellularity and heterocyte formation. Explanations about the gene function are given at the bottom. The right column shows micrographs of isolates (or representatives) whose genomes were investigated in this study. Scale bars are $10 \mu \mathrm{m}$. 


\section{Results}

The overall results comprising morphology studied under different culture conditions, media and substrates, $16 \mathrm{~S}$ rRNA based phylogeny and main informative domains of the secondary structures of the 16S-23S ITS sequence led to the conclusion that strain PCC 6712 must be assigned to the genus Hyella in the order Pleurocapsales. This is corroborated by in-depth analyses of biosynthetic gene clusters responsible for, e.g., multicellularity and nitrogen fixation obtained from comparisons on genome level; thus, it is now formally described as $H$. disjuncta sp. nov. PCC 6712.

In detail, $H$. disjuncta PCC 6712 clusters together with $H$. patelloides LEGE 07179 within the order Pleurocapsales based on the 16S rRNA (Figure 1). Related clusters within the Pleurocapsales are formed by Xenococcus (Figure 1). The Pleurocapsales represent a monophyletic order significantly different from, e.g., Chroococcidiopsidales or Chroococcales, both orders to which the strain was previously assigned. The D1-D1' domain within the secondary structures of the 16S-23S ITS indicates a bigger loop structure in the stalk for $H$. disjuncta PCC 6712 compared to H. patelloides LEGE 07179 as well as a single loop structure in the Box B domain (Figure 2).

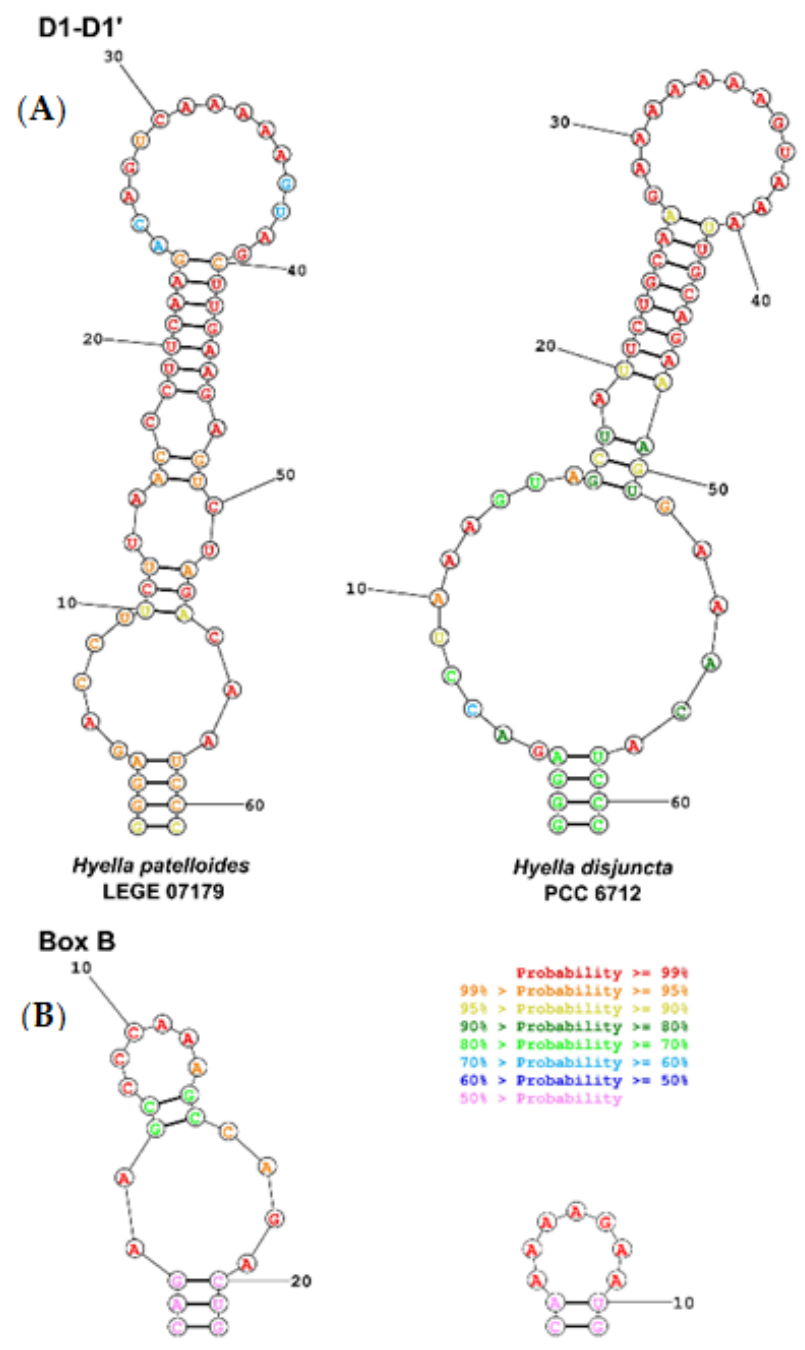

Figure 2. Predicted secondary structures of the 16S-23S rRNA ITS regions of $H$. patelloides LEGE 07179 and H. disjuncta PCC 6712. (A) D1-D1' helix, (B) Box-B helix.

The morphology of $H$. disjuncta PCC 6712 was found to be stable and uniform during three months of investigations under cultivation in liquid and solidified BG11 and NM medium, on basalt and quartz sand. No growth was detected on nitrogen-free BG11 medium during three months of cultivation; instead, chlorosis could be observed followed 
by a rapid recovery once transferred to BG11 with nitrogen. H. disjuncta PCC 6712 is marked by a loose arrangement of mainly single, unicellular cells of brown to blue-green and purple color (Figure 3). Single cells are enclosed in a colorless, hyaline sheath that is not diffluent and regularly comprises no more than a dozen cells and also baeocytes. Short pseudofilaments were only rarely observed. Cells divide mainly by timed binary fission in more than one successive plane (Figure 3C-E). Reproduction by baeocytes comprising up to eight cells was observed. The strain was found to be non-motile during all life stages. The irregular arrangement of thylakoid membranes is visible already under the light microscope indicated by, e.g., irregular shadings in the cells. The rare formation of short pseudofilaments as well as the single cell formation in H. disjuncta sp. nov. PCC 6712 are the main features to discriminate against $H$. patelloides.

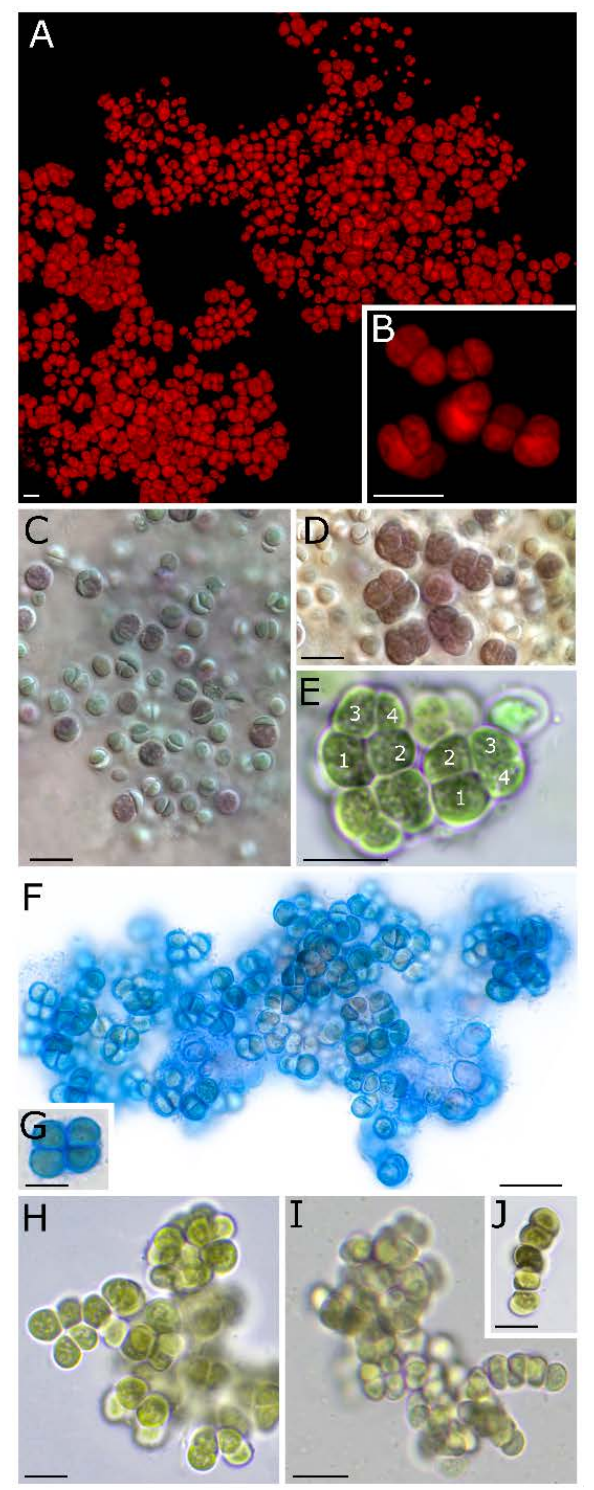

Figure 3. Morphology of Hyella disjuncta sp. nov. PCC 6712. (A,B) Fluorescence microscopy showing the loose, single-cell structure of $H$. disjuncta PCC 6712, as well as a coiled thylakoid structure reaching up to central parts of the cells. (C,D) Differential interference contrast (DIC) images of ensheathed single cells in (C) and baeocytes made of only a few cells in (D). (E) Baeocyte formation by timed successive binary fission resulting in cells of different sizes corresponding to their age (indicated by numbers). (F,G) ACN staining showing tight, capsule-like sheath material in blue. (H-J) Rare formation of short pseudofilaments with cells that are loosely held together by their sheaths. 


\subsection{Genomic Analysis of Hyella Disjuncta PCC 6712}

The genome of H. disjuncta PCC 6712 was sequenced and published by Shih et al. 2013 [15] and a comparison with $H$. patelloides LEGE 07179 (as reference genome) was performed by Brito et al. 2020 [14]. Here, we have expanded the genomic analysis of H. disjuncta PCC 6712 to include genes involved in multicellularity, nitrogen fixation, the presence of encoded BGCs (AntiSMASH) and potential antibiotic resistance mechanisms (ARTS 2.0).

\subsubsection{Genes Involved in Multicellularity}

The genus Hyella is characterized by the formation of pseudofilaments, often described as a loose cell-cell contact, where cells are held together mainly by their sheaths, called 'articuli disjuncti' [55]. While other characterized Hyella species form long pseudofilaments, we found these rarely occurring in $H$. disjuncta PCC 6712. Thus, a genomic comparison of H. disjuncta PCC 6712 with H. patelloides LEGE 07179 and selected species within Chroococcaceae, Synechococcus, Gloeocapsa and Nostocaceae were surveyed targeting genes known to be involved in cellular differentiation and multicellularity (Figure 1). In comparison to filament-forming Nostocales, all investigated pleurocapsalean strains including both $H$. disjuncta PCC 6712 and H. patelloides LEGE 07179 were highly conserved across all searched genes, missing genes known for their role during multicellularity (sepJ (fraG), fraC, fraD and amiC2). Interestingly, the cydiv gene was present in all Chroococcidiopsidales, such as Chroococcidiopsis thermalis PCC 7203, Gloeocapsopsis dulcis AAB1, Gloeocapsa sp. PCC 7428, all Nostocales and Pleurocapsa sp. PCC 7327, but not in any other searched Pleurocapsales.

The ami operon has also been found to play a significant role in multicellularity, where Nostocacales appear to encode two copies of the amiC (amiC1 and amiC2) gene, while other lineages appear to have a single copy [31]. As expected, both Hyella species contained only amiC1 in addition to the highly conserved glutamine racemace (mucl) and a synthase type gene, which has distinct annotations but appeared to have sequence similarity based on clinker alignment. The synthase-type gene was also present in Nostoc, Gleocapsopsis and Synechococcus, but not in Pleurocapsa sp. PCC 7319 (Figure 4). Other genes were also conserved within the Hyella genus including ferrochelatase, UDP-glucose 4-epimerase (present only in Pleurocapsales) and hypothetical proteins. Stanieria sp. and P. cyanobacterium LEGE 10410 also showed high similarity to the Hyella amiC genetic loci; however, it also encoded an additional $\mathrm{Na} / \mathrm{H}+$ antiporter similar to both Nostocales and Synechococcus elongates PCC 6301, while this was absent in Hyella.

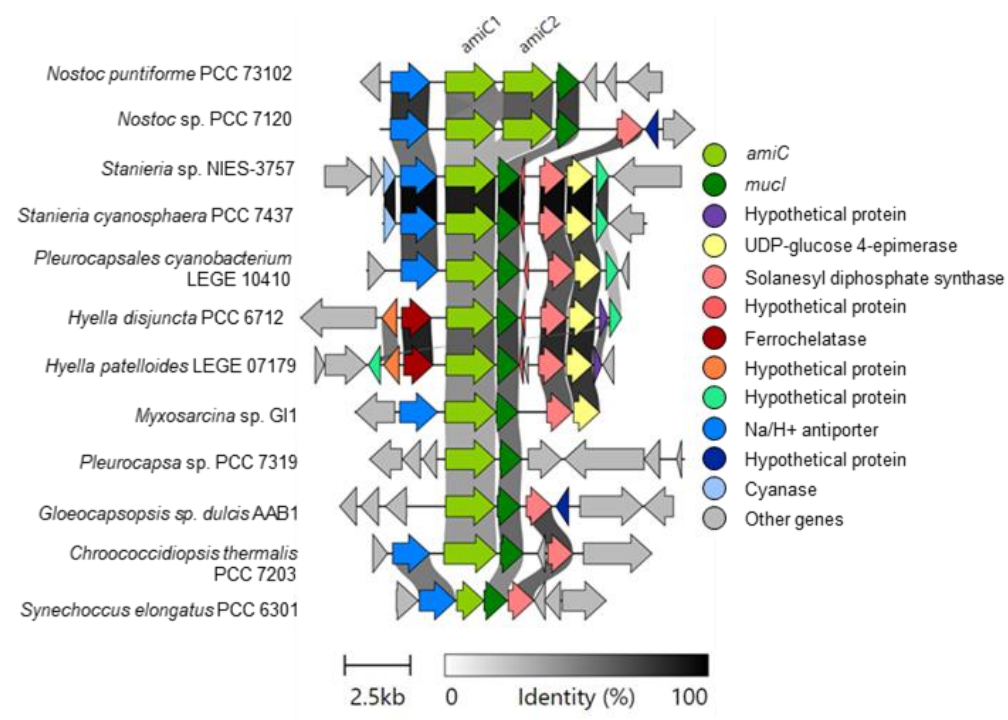

Figure 4. Genomic analysis of the amiC operon. Gene similarity cutoff is $0.3(30 \%)$ and cluster alignments are centered using amiC1. Xenococcus sp. PCC 7305 did encode amiC1 and mucI, but this is not shown because $\mathrm{mucl}$ is on the edge of a contig. 


\subsubsection{Genes Involved in Nitrogen Metabolism}

A genomic screen of the nif (nitrogen metabolism) gene cluster was also performed on Hyella disjuncta PCC 6712 compared to related organisms. We report here, in agreement with the literature, the inability of the H. disjuncta PCC 6712 to grow on nitrogen-deficient medium [5] although we were able to identify the nif gene cluster within its genome. The nif cluster could not be identified in several other Pleurocapsales genomes, being absent from Pleurocapsales cyanobacterium LEGE 10410 and both species of Stanieria, while the nif cluster was identified in Myxosarcina sp. GI1 and showed very similar gene synteny (similar blocks of genes in the same relative positions in the genome) to other Pleurocapsales. However, the cluster was on the edge of a contig and could not be analyzed in full (Figure 5). A comparison of the nif gene cluster to other cyanobacteria with well-characterized nif pathways showed that genomic synteny of $H$. disjuncta PCC 6712 nif appeared most closely to $P$. cyanobacterium LEGE 10410 and not $H$. patelloides LEGE 07179, while H. patelloides LEGE 07179 appeared to most closely resemble the Xenococcus sp. PCC 7305 nif pathway. Furthermore, there was observed diversity between these nif clusters, Pleurocapsa sp. PCC 7327 and Chroococcidiopsis thermalis PCC 7203, particularly in regards to the feo genes and the regulator $c n f R$ [56] (Figure 5).

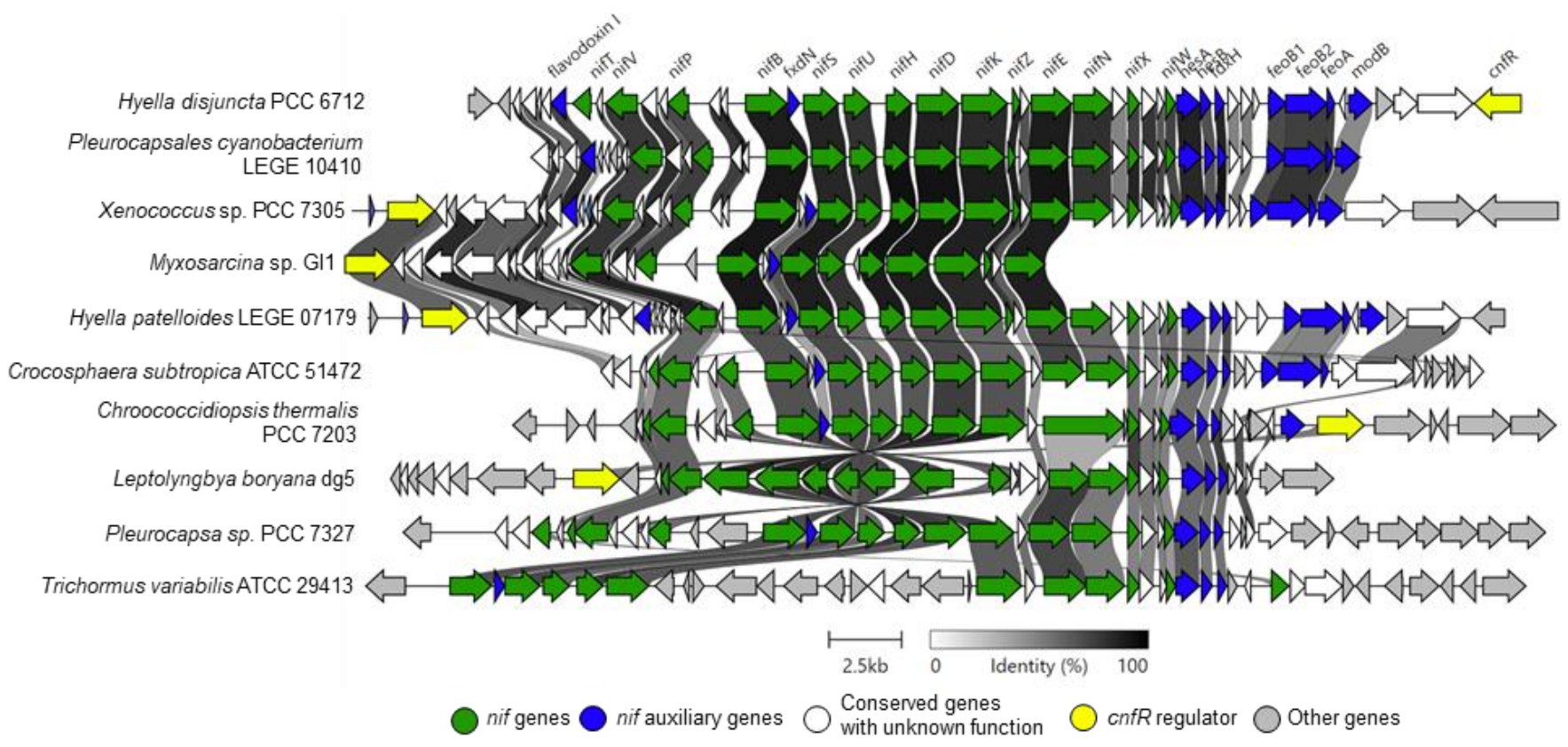

Figure 5. Genomic analysis of the nif pathway. Gene similarity cutoff is $0.3(30 \%)$ and cluster alignments are centered using nifX.

\subsubsection{Genome Mining Analysis}

The genome of $H$. disjuncta PCC 6712 was submitted to AntiSMASH version 6.0 and ARTS 2.0 for detection of BGCs and the possibility of gene duplication as resistance mechanisms. AntiSMASH analysis revealed a total of 13 BGCs (Supplementary Table S1). A total of 10 pathways did not show any similarity to known pathways, two showed very low similarity $(<30 \%)$ and one showed similarity to the known 1-heptadecene pathway. The 1-heptadecene pathway is responsible for hydrocarbon production by a terminal olefin and was previously identified in other baeocyte-forming strains [57,58]. The 12 cryptic BCGs consisted of three non-ribosomal peptide synthetase/polyketide synthase (NRPS/PKS) hybrid, two type-I PKS, four Lanthipeptide RiPPs, two terpene BGCs and one mixed typeIII PKS and terpene BGC. These BGCs are likely to produce a broad range of potentially unknown natural products. 
Analysis of AntiSMASH identified BGCs within the H. disjuncta PCC 6712 genome revealed several characteristics. For example, the two BGCs (Region 3.3 and 3.11) encoded halogenases with Region 3.3 encoding four halogenases genes within a single pathway. This pathway shared similarities (although differences in the number of halogenases) to several non-Pleurocapsales cyanobacteria, including representatives of the genera Chondrocystis, Gloeothece, Fischerella and Microcystis. Another interesting phenomenon included the high number of glycosyltransferases observed. A total of 5 out of 13 BGCs (Region 3.3, 3.6, 3.7, 3.8 and 3.12) were clustered with glycosyltransferase-like genes, including the PKS-I Region 3.6, which encoded a total of 13 glycosyltransferase-type genes, indicating the likelihood of multiple highly glycosylated natural products.

Comparison of the H. disjuncta PCC 6712 within the AntiSMASH framework was used to identify BGCs that may be present in other cyanobacterial genomes or are likely to be species/strain specific. Interestingly, none of the cryptic BGCs were present in H. patelloides LEGE 07179 as a result of the AntiSMASH search, although Brito et al. 2020 [14] found similarities in gene cluster families between the two organisms when using BiG-SCAPE analysis with a 0.7 cut-off which included a single terpene BGC (Region 3.11) and the NRPS-like gene cluster corresponding to the known 1-heptadecene pathway (Region 3.9).

In addition to AntiSMASH-identified BGCs, $H$. disjuncta PCC 6712 has previously been reported to encode the known MAA (UV-absorbing sunscreens) pathway (mys) [50], although it was not detected by AntiSMASH. Comparison of the mys pathway was performed against all Pleurocapsales, Chroococcidiopsis thermalis PCC 7203 and both Nostoc punctiforme PCC 73102 and Trichormus (Anabaena) variabilis ATCC 29413 as characterized reference pathways [51,52] (Figure 6). H. disjuncta PCC 6712 and H. patelloides LEGE 07179 encode distinct mys BGCs, yet both form an N. punctiforme PCC 73102-type mys gene cluster, since they include $m y s D$ (D-ala-D-ala ligase), in contrast to all other Pleurocaspales and analyzed mys pathways, which do not encode mys $D$ or mysE. The absence of mys D and mysE from the majority of Pleurocapsales mys pathways indicates that these organisms may produce distinct MAAs compared to the most commonly identified shinorine biosynthetic route [50,51], and therefore, they could be interesting to further investigate from biosynthetic and novel molecule perspectives.

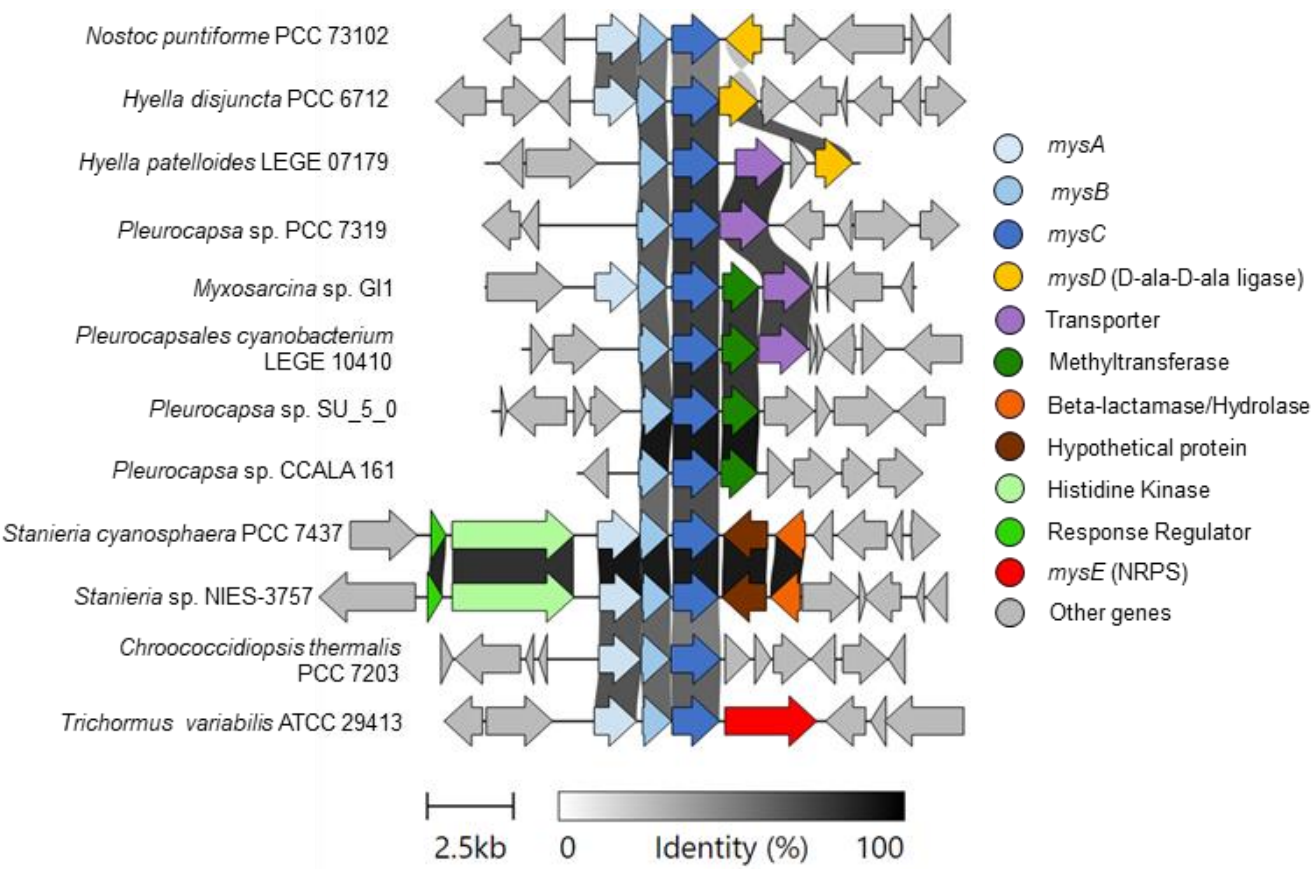

Figure 6. The mys gene cluster throughout Pleurocapsales. Gene similarity cutoff is $0.3(30 \%)$ and cluster alignments are centered using mysC. 
H. patelloides LEGE 07179 also appeared to contain a mys BCG, including two additional genes (a transporter and a GNAT N-acetyltransferase) with unknown biosynthetic function. However, H. patelloides LEGE 07179 appears to have a deletion of the mys A, which was observed across all other Pleurocaspales with the exception of Myxosarcina sp. GI1 and Stanieria sp. A BLASTp search using the $H$. disjuncta PCC 6712 mys $A$ sequence as a query revealed $m y s A$-like homologues in all organisms; however, it is not known if these homologues are involved in MAA biosynthesis.

To further analyze the genome of $H$. disjuncta PCC 6712, we also performed an analysis using ARTS [59], which is used to propose core and resistance genes clustering with BGCs that may indicate possibility of antibiotic production (Supplementary Table S2). ARTS identified 430 core/essential genes and 69 known resistance model hits. A total of 11 BGCs were detected by ARTS. Therefore, there was some discrepancy between AntiSMASH and ARTS BGC identification, where AntiSMASH Region 3.2, 3.5 and 3.13 were not detected by ARTS and one BGC, a bacteriocin, was detected by ARTS and not AntiSMASH. All 11 BGCs were associated with either core resistance ( 9 out of 11$)$, known resistance (1 out of 11) or putative resistance domains of unknown function (9 out of 11) (Supplementary Table S3).

\subsection{Taxonomic Treatment}

Hyella disjuncta sp. nov. P. Jung, P.M. D'Agostino, B. Büdel et M. Lakatos

Description: Thallus coherent, dry, brown, rarely violet-brown on agar. It grows as dense, irregular, pseudo-parenchymatous masses in which many cells have a polygonal shape as a result of close packing. Colonies are made of single cells that are more or less spherical, polygonal rounded or oval of highly variable sizes ((3.2)4.6-5.8(7.2) $\mu \mathrm{m}$ in diameter) and a vivid blue-green, purple-violet to brownish color. Cell content is irregularly distributed, including granular inclusions, causing an uneven shading pattern that is also characteristic for $H$. patelloides LEGE 07179. Single cells adhere to colonies that can be irregularly rounded to pseu-do-parenchymatous comprising not more than a dozen cells in a common, hyaline, firm and limited capsule-like sheath. Short pseudofilaments of only a few cells in a raw were exceptionally rarely found, sometimes with two dichotomous apical cells. Cells divide mainly by timed binary fission in more than one successive plane, while reproduction by non-motile baeocytes comprising up to eight cells was observed.

Habitat: unnamed freshwater reservoir, Marin County, California.

Etymology: 'disjuncta' Latin, describing the mainly unicellular appearance of the species with disjointed cells loosely held together by their sheath, a stadium common to several species within the genus termed 'articuli disjuncti' by Bornet and Flahaut 1988 [55].

Type location: USA.

Holotype: The preserved holotype specimen of the species is available via Herbarium Hamburgense, Hamburg, Germany (HBG-025124). This was prepared from the living strain.

Reference strain: PCC 6712, synonyms ATCC 27176, CCAP 1411/2, originally reported as Chlorogloea sp. [5], originally isolated by R. Kunisawa in 1967.

Discrimination against other species: Despite all other described Hyella species, H. disjuncta PCC 6712 can be differentiated by being predominantly single-celled, while long pseudofilaments are common for all other species.

Phylogenetic Relations and Secondary Structure of the 16S-23S ITS Sequence: H. disjuncta PCC 6712 forms a separate cluster together with H. patelloides LEGE 07179 within the Pleurocapsales based on the 16S rRNA phylogeny as well as on genome level. The D1-D1' domain within the secondary structures of the 16S-23S ITS indicates a bigger loop structure in the stalk for $H$. disjuncta PCC 6712 compared to H. patelloides LEGE 07179 as well as a single loop structure in the Box B domain (Figure 2).

Additional Information: Stanier et al. 1971 [20] stated a DNA base composition of 40.8 moles \% GC, a maximum tolerable growth temperature of $39^{\circ} \mathrm{C}$ and a resistance to penicillin $\mathrm{G}$ up to at least 50 units $\mathrm{mL}^{-1}$. Bryant 1982 [8] found that the strain produces C-phycoerythrin and exhibits complementary chromatic adaptation of type III (chromati- 
cally adapts by photo-controlling the synthesis of both phycoerythrin and phycocyanin). Cumbers et al. 2014 [12] detected salt tolerance up to $500 \mathrm{mM} \mathrm{(4 \% )} \mathrm{describing} \mathrm{the} \mathrm{strain} \mathrm{as}$ euryhaline although it is a freshwater isolate and Lorne et al. 2000 [60] found the kaiC gene cluster present, a factor involved in controlling the circadian rhythm. The fatty acid profile of the strain was previously analyzed and can be consolidated [10].

\section{Discussion}

\subsection{Taxonomic Notes on the Genus Hyella}

Bornet and Flahault described the genus Hyella in 1888 [55], and found several species that often formed polarized pseudofilaments drilling into the carbonate shells of molluscs in marine habitats. Their early findings were based on the species $H$. caespitosa; its complex life cycle and morphology is described in depth by Le Campion-Alsumand and Golubić 1985 [61], ranging from unicellular single celled-stadia, baeocyte formation and H-shaped gelatinous cushion formation between cells up to complex branching patterns of wellexpressed pseudofilaments. Comparable morphological characteristics were also described for H. balani [61] and H. patelloides LEGE 07179 [14]. Besides well-documented morphological comparisons, only a few isolates made their way into public culture collections, allowing a thorough analysis of their taxonomy corroborated by modern phylogenetic tools such as 16S rRNA or whole genome sequencing. In 2017, H. patelloides LEGE 07179 was described using the polyphasic approach by Brito et al. [14] without including the $16 \mathrm{~S}$ rRNA sequence of strain 'Pleurocapsa sp.' PCC 7516 that was deposited as type strain for the genus as H. caespitosa at PCC in 1974 by T. Le Campion-Alsumard, who isolated it from a rock chip at Station B, L'lle Riou, Calanque des Contrebandiers, Marseille, France [7,17]. Our investigations presented here include H. patelloides LEGE 07179, the herein described species H. disjuncta PCC 6712 and, in addition, the type strain 'Pleurocapsa sp.' PCC 7516 (Hyella caespitosa). A clear relation between H. disjuncta PCC 6712 and H. patelloides LEGE 07179 in great distance to H. caespitosa could be found based on the 16S rRNA what leads to a presumable polyphyly of the genus Hyella (Figure 1). We acknowledge this issue because the correct taxonomic evaluation of $H$. patelloides LEGE 07179 and the resulting description considering modern standards is thoroughly conducted, whereas this is missing for the presumed type strain 'Pleurocapsa sp.' PCC 7516 [62]. Additionally, even on a genome level, phylogeny H. patelloides LEGE 07179 and H. disjuncta PCC 6712 form a distinct cluster at the same position they can be found in the phylogenetic analysis based solely on the $16 \mathrm{~S}$ rRNA [14]. In a recent phylogenetic study, the strain Pleurocapsa sp. PCC 7516 was integrated as a type strain and some closely clustering $16 \mathrm{~S}$ rRNA sequences from uncultured and a few cultured strains were considered as additional Hyella strains [3]. It should be noted that in their study, the morphology of the strains was not studied and those suggestions were solely based on the cluster formation of the strain's 16S rRNA sequences [3]. We cannot support these results, but we considered them during our phylogenetic analysis (Figure 1). However, the current polyphyly of the genus will certainly be resolved in the near future when studies combining molecular, morphological and ecological data might re-structure these pleurocapsalean genera and species.

\subsection{Taxonomic Notes on the Strain Hyella disjuncta PCC 6712, Formerly Chroococcidiopsis sp. PCC 6712}

Since its isolation, $H$. disjuncta PCC 6712 has confused taxonomists, which has led to constant taxonomic changes owed to methodological restrictions at that time. It was first classified as the nostocalean Chlorogloea sp. [5]. However, it was later noticed that strain PCC 6712 was unable to grow on nitrogen-free medium, an ability that usually all Nostocales share. Based on these doubts and the first genetic analyses, the strain was later placed into the chroococcidiospisidalean genus Chroococcidiopsis [6], but morphological differences between H. disjuncta PCC 6712 and other Chroococcidiopsis strains were noticed that again rang the alarm. Additionally, this misinterpretation was likely also supported by 
the finding of non-motile baeocytes in strain PCC 6712, which is considered a characteristic feature for non-pleurocapsalean taxa $[18,19]$.

Similarities between H. disjuncta PCC 6712 and H. patelloides LEGE 07179 can also be found based on morphology, especially during the single-celled stadium of H. patelloides LEGE 07179 [16] (Figure 5), which resembles those of the unicellular and single celled H. disjuncta PCC 6712. However, both strains can be differentiated by the prominent formation of pseudofilaments of $H$. patelloides LEGE 07179 , which remains very weakly and rarely expressed in H. disjuncta PCC 6712 (Figure 1) and all other described Hyella species. The rather unicellular appearance of $H$. disjuncta PCC 6712 might be confusing because the formation of pseudofilaments was considered to be a strict morphological feature of the genus Hyella [55], but unicellular, coccoid stages were already described by Bornet and Flahault in 1888, termed articuli disjuncti. They recognized that cells of $H$. caespitosa, the type strain of the genus, were disjointed and can form cellular series rather than trichomes and filaments (=pseudofilaments) and that cells are rather held together only by enclosing sheaths. The coccoid form might be overexpressed in $H$. disjuncta compared to other described Hyella species, but this characteristic remained stable since the isolation of the strain and also did not change under various cultivation conditions, such as growth on basalt or sand, as tested in our study over the course of three months.

Genes responsible for nitrogen fixation were also detected in $H$. patelloides LEGE 07179 [16], but at the same time, they reported no growth on nitrogen-free medium, similar to our findings for $\mathrm{H}$. disjuncta PCC 6712, which also encoded the full nif cluster (Figure 5). Interestingly, the nif cluster was absent from multiple Pleurocapsales. This raises the question if the ability of nitrogen fixation has been lost in all Pleurocapsales or if nitrogen fixation is only possible under specific circumstances, such as during the dark phase of growth or in light at a time when photosynthesis is inhibited [63].

Surprisingly, the formally strain Chroococcidiopsis sp. (now H. disjuncta PCC 6712) was found to have non-motile baeocytes by Waterbury and Stanier already in 1978 [7] (Figure 3C), which was supported by our findings, questioning if the motility of baeocytes should still be considered as crucial feature reserved for members of the order Pleurocapsales. Unfortunately, it is not known if H. patelloides LEGE 07179 forms motile baeocytes or not [16], but the proposed type strain 'Pleurocapsa sp.' PCC 7516 (H. caespitosa) does have motile baeocytes [7], supporting a re-evaluation of the taxonomic status of the proposed type strain 'Pleurocapsa sp.' PCC 7516 (H. caespitosa) or H. disjuncta and H. patelloides in the future.

\subsection{Genomic and Chemical Notes on the Strain H. disjuncta PCC 6712}

In 2000, the fatty acid profile of many cyanobacterial strains across the phylum, including strain PCC 6712, supported the evidence of taxonomic misassignment and found some overlap to pleurocapsalean strains [10]. This was further elucidated by full $16 \mathrm{~S}$ rRNA sequencing and phylogenetic analyses in 2001, where a placement within the order Pleurocapsales was supported [4], and has since been linked to the 1-heptadecine BGC (Region 3.9) [14]. The BGC encodes a PKS-I like pathway beginning with a fatty acid ligase, usually known to incorporate a long fatty acid chain [57], followed by a single partially reducing PKS module with domain architecture acyl carrier protein (ACP), ketosynthase, acyltransferase, ketoreductase, a second $\mathrm{ACP}$, sulfotransferase and finally a hydrolase domain. Previous sequence analysis has revealed that this BGC is involved in the production of a terminal olefins by an olefin synthase (OLS) of the CF- 8 family [64], with the gene phylogenetically most closely related to Xenococcus sp. PCC 7305 and H. patelloides LEGE 07179 based on gene cluster family analysis [14,58]. As suggested by Brito et al. and Zhu et al., these phylogenetic and hydrocarbon analysis profiles corresponded with taxonomy, with $\mathrm{H}$. disjuncta PCC 6712 producing low levels of polyunsaturated acids while strains of Chroococcidiopsis reported high levels polyunsaturated acids $[10,57,58]$. Fatty acid composition analysis also revealed that $\mathrm{C} 15$ hydrocarbon production by $\mathrm{H}$. disjuncta PCC 6712 was similar to that of the closely related H. patelloides LEGE 07179 and Xeno- 
coccus but distinct from other members of the Pleurocapsales, such as Stanieria sp. [10]. Overall, these data support the assignment of PCC 6712 as a new species of Hyella and not Chroococcidiopsis.

To further support the morphological and phylogenetic results presented in this study, a genomic approach was used to compare $H$. disjuncta PCC 6712 with related cyanobacteria. A complete genome wide comparison between $H$. disjuncta PCC 6712 and the most closely related H. patelloides LEGE 07179 was recently performed by Brito et al. 2020 [14], and found to share $3619(44.7 \%)$ orthologues and $2256(27.8 \%)$ paralogs, while $2229(27.5 \%)$ did not have any similarity.

While the genomes of the two organisms appear relatively similar, there have been observed differences in the formation of pseudofilaments, where all Hyella are capable of pseudofilament formation, but this seems to very rarely occur in H. disjuncta PCC 6712. H. disjuncta PCC 6712 encoded all multicellular genes present across Hyella and closely related Pleurocapsales. Surprisingly, all Pleurocapsales missed the cydiv (Cyanobacteria Division) gene, which encodes a conserved hypothetical protein [45]. Recent localization and partial deletion mutant experiments in Nostoc sp. PCC 7120 implicated cydiv in filamentous cyanobacterial cell division. Furthermore, cydiv could not be completely knocked out, indicating it is an essential gene. Interestingly, cydiv was present in all investigated Chroococcidiopsidales and Nostocales and Urrejola et al. 2021 [31] already speculated that members of the Chroococcidiopsidales, such as Gloeocapsopsis dulcis AAB1, might have lost the ability of multicellularity. However, they assumed that cell-cell interaction is still present during, e.g., dyade or tetrade formation or among baeocytes. This is supported by short pseudofilaments built by linearly arranged cells in Chroococcidiopsis muralis [65], a unique finding for Chroococcidiopsidales. However, this information is accurate because the phylogenetic tree prepared by the authors based on the $16 \mathrm{~S}$ rRNA shows a clear assignment to the genus Chroococcidiopsis sensu stricto, although the morphological abnormality of pseudofilaments is intriguing and worth further investigations regarding multicellularity. The lack of genes so far known to be involved in multicellularity in H. disjuncta PCC 6712 and H. patelloides LEGE 07179 linked to pseudofilament formation in H. patelloides LEGE 07179 indicates that unknown genes are certainly involved in multicellularity. Due to their high genomic congruence and the distinct discrimination feature of pseudofilament formation in H. patelloides LEGE 07179 and the absence of the latter in H. disjuncta PCC 6712 makes both species suitable objects for future investigations of multicellularity.

Genome mining is an important strategy in the discovery of novel and bioactive natural products. Similar to the results of Brito et al. [14] in regards to the presence of strain-specific BGCs encoded within Hyella genomes, H. disjuncta PCC 6712 was also found to encode unique BGCs that do not seem to be present within the known cyanobacterial genetic data. Interestingly, several pathways were found to encode halogenases and glycosyltransferases. Halogenated and glycosylated natural products have been shown to display high rates of bioactivity and intriguing structural diversity [66,67] and are, therefore, potent targets for drug discovery. Unfortunately, the products of these cryptic pathways remain unknown. Thus, these results support the hypothesis that the Hyella genus appears to be a prolific source of cryptic BGCs and potential bioactive natural products. Interestingly, H. disjuncta PCC 6712 and H. patelloides LEGE 07179 appear to code a very high number of intriguing and unique BGCs, and therefore, this genus is an attractive target for future bioactive natural product discovery.

\section{Conclusions}

The combination of genome mining (e.g., for potential bioactivity, multicellularity, nitrogen fixation, MAA) and polyphasic evaluation comprising morphology, 16S rRNAbased phylogeny and main informative domains of the secondary structures of the 16S-23S ITS domains offers not only information to classify isolated strains within the phylogeny of cyanobacteria, it also gives insides in the functionality of genes between clades and point to specific clades which could be interesting for biotechnology. 
Moreover, this study emphasizes that ignoring morphological features and focusing only on genetic- or genome-based phylogenetics to propose new genera and species concepts $[68,69]$ without giving genus and species descriptions of the investigated strains, leads to confusion and frequent revisions of the taxonomic concept. Currently, taxonomic concepts purely based on genetics have not gained acceptance among cyanobacterial taxonomists and, for example, the establishment of type strains solely on genome data has just recently been rejected by the International Committee on Systematics of Prokaryotes (the committee which governs the Prokaryotic Code) [70,71].

The future taxonomic evaluation of additional Hyella-like cyanobacterial strains will likely tackle the current discrepancy that is raised between the phylogeny and morphology of the supposed type strain 'Pleurocapsa sp. PCC 7516' (Hyella caespitosa) and H. patelloides LEGE 07179/H. disjuncta sp. nov. PCC 6712.

Supplementary Materials: The following are available online at https://www.mdpi.com/article/ 10.3390/life11090916/s1, Table S1: AntiSMASH Summary Hits; Table S2: ARTS Core Summary Hits; Table S3: BGC Proximity Analysis; Table S4: Resistance Models; Table S5: Duplication Hits.

Author Contributions: Conceptualization, P.J., P.M.D. and M.L.; methodology, P.J., P.M.D. and K.B.; writing-original draft preparation, P.J. and P.M.D.; writing-review and editing, B.B., M.L. and P.M.D.; visualization, P.J. and P.M.D.; supervision, M.L. and B.B.; funding acquisition, M.L. All authors have read and agreed to the published version of the manuscript.

Funding: This research was funded by the European Regional Development Fund ERDF Photoproma (ERDF-EC Ref. 84003265).

Institutional Review Board Statement: This study did not involve humans or animals.

Informed Consent Statement: Not applicable.

Data Availability Statement: Generated sequences can be found as stated under the species description.

Acknowledgments: P.J. wants to thank the University of Applied Sciences Kaiserslautern for additional internal funding, Angela Brito for providing microscopic images depicting Hyella patelloides and Maike Lorenz from the SAG culture collection Göttingen for providing microscopic images of Hyella caespitosa.

Conflicts of Interest: The authors declare no conflict of interest.

\section{References}

1. Komárek, J.; Kaštovský, J.; Mareš, J.; Johansen, J. Taxonomic classification of cyanoprokaryotes (cyanobacterial genera) 2014, using a polyphasic approach. Preslia 2014, 86, 295-335.

2. Mareš, J. Multilocus and SSU rRNA gene phylogenetic analyses of available cyanobacterial genomes, and their relation to the current taxonomic system. Hydrobiologia 2018, 811, 19-34. [CrossRef]

3. Shalygin, S.; Kavulcik, K.J.; Pietrasiak, N.; Bohunicka, M.; Vaccarina, M.A.; Chesarino, N.M.; Johansen, J.R. Neotypification of Pleurocapsa fuliginosa and epitypification of P. minor (Pleurocapsales): Resolving a polyphyletic cyanobacterial genus. Phytotaxa 2019, 392, 245. [CrossRef]

4. Fewer, D.; Friedl, T.; Büdel, B. Chroococcidiopsis and heterocyst-differentiating cyanobacteria are each other's closest living relatives. Mol. Phylogenet. Evol. 2002, 23, 82-90. [CrossRef]

5. Kenyon, C.N.; Rippka, R.; Stanier, R.Y. Fatty acid composition and physiological properties of some filamentous blue-green algae. Arch. Mikrobiol. 1972, 83, 216-236. [CrossRef]

6. Waterbury, J.B. Order Chroococcales. Bergey's Man. Syst. Bacteriol. 1989, 3, 1728-1746.

7. Waterbury, J.B.; Stanier, R.Y. Patterns of growth and development in pleurocapsalean cyanobacteria. Microbiol. Rev. 1978, $42,2-44$. [CrossRef] [PubMed]

8. Bryant, D.A. Phycoerythrocyanin and Phycoerythrin: Properties and Occurrence in Cyanobacteria. Microbiology 1982, 128, 835-844. [CrossRef]

9. Cardellina, J.H.; Kirkup, M.P.; Moore, R.E.; Mynderse, J.S.; Seff, K.; Simmons, C.J. Hyellazone and chlorohyellazole, two novel carbazoles from the blue-green alga Hyella caespitosa Born. et Flah. Tetrahedron Lett. 1979, 20, 4915-4916. [CrossRef]

10. Caudales, R.; Wells, J.M.; Butterfield, J.E. Cellular fatty acid composition of cyanobacteria assigned to subsection II, order Pleurocapsales. Int. J. Syst. Evol. Microbiol. 2000, 50 Pt 3, 1029-1034. [CrossRef]

11. Baran, R.; Ivanova, N.N.; Jose, N.; Garcia-Pichel, F.; Kyrpides, N.C.; Gugger, M.; Northen, T.R. Functional genomics of novel secondary metabolites from diverse cyanobacteria using untargeted metabolomics. Mar. Drugs 2013, 11, 3617-3631. [CrossRef] 
12. Cumbers, J.; Rothschild, L.J. Salt tolerance and polyphyly in the cyanobacterium Chroococcidiopsis (Pleurocapsales). J. Phycol. 2014, 50, 472-482. [CrossRef]

13. Willemse, J.; Büke, F.; van Dissel, D.; Grevink, S.; Claessen, D.; van Wezel, G.P. SParticle, an algorithm for the analysis of filamentous microorganisms in submerged cultures. Antonie Van Leeuwenhoek 2018, 111, 171-182. [CrossRef]

14. Brito, Â.; Vieira, J.; Vieira, C.P.; Zhu, T.; Leão, P.N.; Ramos, V.; Lu, X.; Vasconcelos, V.M.; Gugger, M.; Tamagnini, P. Comparative Genomics Discloses the Uniqueness and the Biosynthetic Potential of the Marine Cyanobacterium Hyella patelloides. Front. Microbiol. 2020, 11, 1527. [CrossRef]

15. Shih, P.M.; Wu, D.; Latifi, A.; Axen, S.D.; Fewer, D.P.; Talla, E.; Calteau, A.; Cai, F.; de Marsac, N.T.; Rippka, R.; et al. Improving the coverage of the cyanobacterial phylum using diversity-driven genome sequencing. Proc. Natl. Acad. Sci. USA 2013, 110, 1053-1058. [CrossRef] [PubMed]

16. Brito, Â.; Ramos, V.; Mota, R.; Lima, S.; Santos, A.; Vieira, J.; Vieira, C.P.; Kaštovský, J.; Vasconcelos, V.M.; Tamagnini, P. Description of new genera and species of marine cyanobacteria from the Portuguese Atlantic coast. Mol. Phylogenet. Evol. 2017, 111, 18-34. [CrossRef]

17. Stanier, R.Y.; Deruelles, J.; Rippka, R.; Herdman, M.; Waterbury, J.B. Generic Assignments, Strain Histories and Properties of Pure Cultures of Cyanobacteria. Microbiology 1979, 111, 1-61. [CrossRef]

18. Rippka, R.; Waterbury, J.B.; Herdman, M.; Castenholz, R.W. Pleurocapsa-group. In Bergey's Manual of Systematics of Archaea and Bacteria; Whitman, W.B., Rainey, F., Kämpfer, P., Trujillo, M., Chun, J., DeVos, P., Hedlund, B., Dedysh, S., Eds.; Wiley: Hoboken, NJ, USA, 2015; pp. 1-9. [CrossRef]

19. Rippka, R.; Waterbury, J.B.; Herdman, M.; Castenholz, R.W. Form-Chroococcidiopsis. In Bergey's Manual of Systematics of Archaea and Bacteria; Trujillo, M., Dedysh, S., DeVos, P., Hedlund, B., Kämpfer, P., Rainey, F., Whitman, W.B., Eds.; Wiley: Hoboken, NJ, USA, 2015; pp. 1-5. [CrossRef]

20. Stanier, R.Y.; Kunisawa, R.; Mandel, M.; Cohen-Bazire, G. Purification and properties of unicellular blue-green algae (order Chroococcales). Bacteriol. Rev. 1971, 35, 171-205. [CrossRef]

21. Rippka, R. Recognition and identification of cyanobacteria. In Cyanobacteria; Packer, L., Glazer, A.N., Eds.; Methods in Enzymology, Volume 167; Academic Press: London, UK, 1988; pp. 28-67. ISBN 9780121820688.

22. Wilmotte, A.; van der Auwera, G.; de Wachter, R. Structure of the $16 \mathrm{~S}$ ribosomal RNA of the thermophilic cyanobacterium Chlorogloeopsis HTF ('Mastigocladus laminosus HTF') strain PCC7518, and phylogenetic analysis. FEBS Lett. 1993, 317, 96-100. [CrossRef]

23. Kumar, S.; Stecher, G.; Li, M.; Knyaz, C.; Tamura, K. MEGA X: Molecular Evolutionary Genetics Analysis across Computing Platforms. Mol. Biol. Evol. 2018, 35, 1547-1549. [CrossRef] [PubMed]

24. Ronquist, F.; Huelsenbeck, J.P. MrBayes 3: Bayesian phylogenetic inference under mixed models. Bioinformatics 2003, 19, 1572-1574. [CrossRef]

25. Lemoine, F.; Correia, D.; Lefort, V.; Doppelt-Azeroual, O.; Mareuil, F.; Cohen-Boulakia, S.; Gascuel, O. NGPhylogeny.fr: New generation phylogenetic services for non-specialists. Nucleic Acids Res. 2019, 47, W260-W265. [CrossRef] [PubMed]

26. Letunic, I.; Bork, P. Interactive Tree Of Life (iTOL) v5: An online tool for phylogenetic tree display and annotation. Nucleic Acids Res. 2021, 49, W293-W296. [CrossRef]

27. Reuter, J.S.; Mathews, D.H. RNAstructure: Software for RNA secondary structure prediction and analysis. BMC Bioinform. 2010, 11, 129. [CrossRef]

28. Turland, N.; Wiersema, J.; Barrie, F.; Greuter, W.; Hawksworth, D.; Herendeen, P.; Knapp, S.; Kusber, W.-H.; Li, D.-Z.; Marhold, K.; et al. International Code of Nomenclature for Algae, Fungi, and Plants; Koeltz Botanical Books: Kelkheim, Germany, 2018. [CrossRef]

29. Gilchrist, C.L.; Booth, T.J.; van Wersch, B.; van Grieken, L.; Medema, M.H.; Chooi, Y.-H. cblaster: A remote search tool for rapid identification and visualisation of homologous gene clusters. bioRxiv 2020. [CrossRef]

30. Gilchrist, C.L.M.; Chooi, Y.-H. Clinker \& clustermap.js: Automatic generation of gene cluster comparison figures. Bioinformatics 2021. [CrossRef]

31. Urrejola, C.; von Dassow, P.; van den Engh, G.; Salas, L.; Mullineaux, C.W.; Vicuña, R.; Sánchez-Baracaldo, P. Loss of Filamentous Multicellularity in Cyanobacteria: The Extremophile Gloeocapsopsis sp. Strain UTEX B3054 Retained Multicellular Features at the Genomic and Behavioral Levels. J. Bacteriol. 2020, 202. [CrossRef]

32. Stucken, K.; John, U.; Cembella, A.; Murillo, A.A.; Soto-Liebe, K.; Fuentes-Valdés, J.J.; Friedel, M.; Plominsky, A.M.; Vásquez, M.; Glöckner, G. The smallest known genomes of multicellular and toxic cyanobacteria: Comparison, minimal gene sets for linked traits and the evolutionary implications. PLOS ONE 2010, 5, e9235. [CrossRef]

33. Nürnberg, D.J.; Mariscal, V.; Bornikoel, J.; Nieves-Morión, M.; Krauß, N.; Herrero, A.; Maldener, I.; Flores, E.; Mullineaux, C.W. Intercellular diffusion of a fluorescent sucrose analog via the septal junctions in a filamentous cyanobacterium. $m B i o$ 2015, 6, e02109. [CrossRef] [PubMed]

34. Weiss, G.L.; Kieninger, A.-K.; Maldener, I.; Forchhammer, K.; Pilhofer, M. Structure and Function of a Bacterial Gap Junction Analog. Cell 2019, 178, 374-384.e15. [CrossRef] [PubMed]

35. Flores, E.; Nieves-Morión, M.; Mullineaux, C.W. Cyanobacterial Septal Junctions: Properties and Regulation. Life 2018, 9 , 1. [CrossRef] [PubMed] 
36. Merino-Puerto, V.; Schwarz, H.; Maldener, I.; Mariscal, V.; Mullineaux, C.W.; Herrero, A.; Flores, E. FraC/FraD-dependent intercellular molecular exchange in the filaments of a heterocyst-forming cyanobacterium, Anabaena sp. Mol. Microbiol. 2011, 82, 87-98. [CrossRef] [PubMed]

37. Flores, E.; Pernil, R.; Muro-Pastor, A.M.; Mariscal, V.; Maldener, I.; Lechno-Yossef, S.; Fan, Q.; Wolk, C.P.; Herrero, A. Septumlocalized protein required for filament integrity and diazotrophy in the heterocyst-forming cyanobacterium Anabaena sp. strain PCC 7120. J. Bacteriol. 2007, 189, 3884-3890. [CrossRef]

38. Merino-Puerto, V.; Mariscal, V.; Mullineaux, C.W.; Herrero, A.; Flores, E. Fra proteins influencing filament integrity, diazotrophy and localization of septal protein SepJ in the heterocyst-forming cyanobacterium Anabaena sp. Mol. Microbiol. 2010, 75, 1159-1170. [CrossRef]

39. Bornikoel, J.; Carrión, A.; Fan, Q.; Flores, E.; Forchhammer, K.; Mariscal, V.; Mullineaux, C.W.; Perez, R.; Silber, N.; Wolk, C.P.; et al. Role of Two Cell Wall Amidases in Septal Junction and Nanopore Formation in the Multicellular Cyanobacterium Anabaena sp. PCC 7120. Front. Cell. Infect. Microbiol. 2017, 7, 386. [CrossRef]

40. Berendt, S.; Lehner, J.; Zhang, Y.V.; Rasse, T.M.; Forchhammer, K.; Maldener, I. Cell wall amidase AmiC1 is required for cellular communication and heterocyst development in the cyanobacterium Anabaena PCC 7120 but not for filament integrity. J. Bacteriol. 2012, 194, 5218-5227. [CrossRef]

41. Zheng, Z.; Omairi-Nasser, A.; Li, X.; Dong, C.; Lin, Y.; Haselkorn, R.; Zhao, J. An amidase is required for proper intercellular communication in the filamentous cyanobacterium Anabaena sp. PCC 7120. Proc. Natl. Acad. Sci. USA 2017, 114, E1405-E1412. [CrossRef]

42. Videau, P.; Rivers, O.S.; Ushijima, B.; Oshiro, R.T.; Kim, M.J.; Philmus, B.; Cozy, L.M. Mutation of the murC and murB Genes Impairs Heterocyst Differentiation in Anabaena sp. Strain PCC 7120. J. Bacteriol. 2016, 198, 1196-1206. [CrossRef]

43. Velázquez-Suárez, C.; Luque, I.; Herrero, A. The Inorganic Nutrient Regime and the mre Genes Regulate Cell and Filament Size and Morphology in the Phototrophic Multicellular Bacterium Anabaena. mSphere 2020, 5. [CrossRef]

44. Burnat, M.; Schleiff, E.; Flores, E. Cell envelope components influencing filament length in the heterocyst-forming cyanobacterium Anabaena sp. strain PCC 7120. J. Bacteriol. 2014, 196, 4026-4035. [CrossRef] [PubMed]

45. Mandakovic, D.; Trigo, C.; Andrade, D.; Riquelme, B.; Gómez-Lillo, G.; Soto-Liebe, K.; Díez, B.; Vásquez, M. CyDiv, a Conserved and Novel Filamentous Cyanobacterial Cell Division Protein Involved in Septum Localization. Front. Microbiol. $2016,7,94$. [CrossRef]

46. Du, Y.; Zhang, H.; Wang, H.; Wang, S.; Lei, Q.; Li, C.; Kong, R.; Xu, X. Expression from DIF1-motif promoters of hetR and patS is dependent on HetZ and modulated by PatU3 during heterocyst differentiation. PLoS ONE 2020, 15, e0232383. [CrossRef]

47. Jung, P.; Azua-Bustos, A.; Gonzalez-Silva, C.; Mikhailyuk, T.; Zabicki, D.; Holzinger, A.; Lakatos, M.; Büdel, B. Emendation of the Coccoid Cyanobacterial Genus Gloeocapsopsis and Description of the New Species Gloeocapsopsis diffluens sp. nov. and Gloeocapsopsis dulcis sp. nov. Isolated From the Coastal Range of the Atacama Desert (Chile). Front. Microbiol. 2021, $12,1628$. [CrossRef]

48. Thiel, T. Organization and regulation of cyanobacterial nif gene clusters: Implications for nitrogenase expression in plant cells. FEMS Microbiol. Lett. 2019, 366. [CrossRef] [PubMed]

49. Rettberg, L.A.; Wilcoxen, J.; Jasniewski, A.J.; Lee, C.C.; Tanifuji, K.; Hu, Y.; Britt, R.D.; Ribbe, M.W. Identity and function of an essential nitrogen ligand of the nitrogenase cofactor biosynthesis protein NifB. Nat. Commun. 2020, 11, 1-8. [CrossRef] [PubMed]

50. D'Agostino, P.M.; Woodhouse, J.N.; Liew, H.T.; Sehnal, L.; Pickford, R.; Wong, H.L.; Burns, B.P.; Neilan, B.A. Bioinformatic, phylogenetic and chemical analysis of the UV-absorbing compounds scytonemin and mycosporine-like amino acids from the microbial mat communities of Shark Bay, Australia. Environ. Microbiol. 2019, 21, 702-715. [CrossRef] [PubMed]

51. Gao, Q.; Garcia-Pichel, F. An ATP-Grasp Ligase Involved in the Last Biosynthetic Step of the Iminomycosporine Shinorine in Nostoc punctiforme ATCC 29133. J. Bacteriol. 2011, 193, 5923-5928. [CrossRef]

52. Balskus, E.P.; Walsh, C.T. The genetic and molecular basis for sunscreen biosynthesis in cyanobacteria. Science 2010, 329, 1653-1656. [CrossRef]

53. Blin, K.; Shaw, S.; Kloosterman, A.M.; Charlop-Powers, Z.; van Wezel, G.P.; Medema, M.H.; Weber, T. antiSMASH 6.0: Improving cluster detection and comparison capabilities. Nucleic Acids Res. 2021, 49, W29-W35. [CrossRef]

54. Mungan, M.D.; Alanjary, M.; Blin, K.; Weber, T.; Medema, M.H.; Ziemert, N. ARTS 2.0: Feature updates and expansion of the Antibiotic Resistant Target Seeker for comparative genome mining. Nucleic Acids Res. 2020, 48, W546-W552. [CrossRef]

55. Bornet, E.; Flahault, C. Revision des Nostocacées Hétérocystées Contenues Dans les Principaux Herbiers de France; H. R. Engelmann: Brookfield, WI, USA, 1888.

56. Tsujimoto, R.; Kamiya, N.; Fujita, Y. Transcriptional regulators ChlR and CnfR are essential for diazotrophic growth in nonheterocystous cyanobacteria. Proc. Natl. Acad. Sci. USA 2014, 111, 6762-6767. [CrossRef]

57. Coates, R.C.; Podell, S.; Korobeynikov, A.; Lapidus, A.; Pevzner, P.; Sherman, D.H.; Allen, E.E.; Gerwick, L.; Gerwick, W.H. Characterization of cyanobacterial hydrocarbon composition and distribution of biosynthetic pathways. PLoS ONE 2014, 9, e85140. [CrossRef]

58. Zhu, T.; Scalvenzi, T.; Sassoon, N.; Lu, X.; Gugger, M. Terminal Olefin Profiles and Phylogenetic Analyses of Olefin Synthases of Diverse Cyanobacterial Species. Appl. Environ. Microbiol. 2018, 84. [CrossRef] 
59. Alanjary, M.; Kronmiller, B.; Adamek, M.; Blin, K.; Weber, T.; Huson, D.; Philmus, B.; Ziemert, N. The Antibiotic Resistant Target Seeker (ARTS), an exploration engine for antibiotic cluster prioritization and novel drug target discovery. Nucleic Acids Res. 2017, 45, W42-W48. [CrossRef]

60. Lorne, J.; Scheffer, J.; Lee, A.; Painter, M.; Miao, V.P. Genes controlling circadian rhythm are widely distributed in cyanobacteria. FEMS Microbiol. Lett. 2000, 189, 129-133. [CrossRef]

61. LeCampion-Alsumard, T.; Golubi'c, S. Hyella caespitosa Bornet et Flahault and Hyella balani Lehmann (Pleurocapsales, Cyanophyta): A comparative study. Algol. Stud. 1985, 71, 119-148.

62. Castenholz, R.W.; Wilmotte, A.; Herdman, M.; Rippka, R.; Waterbury, J.B.; Iteman, I.; Hoffmann, L.; Phylum, B.X. Cyanobacteria. In Bergey's Manual of Systematic Bacteriology; Boone, D.R., Castenholz, R.W., Garrity, G.M., Eds.; The Archaea and the Deeply Branching and Phototrophic Bacteria; Springer: New York, NY, USA, 2001; Volume 1, pp. 473-599. [CrossRef]

63. Boison, G.; Mergel, A.; Jolkver, H.; Bothe, H. Bacterial life and dinitrogen fixation at a gypsum rock. Appl. Environ. Microbiol. 2004, 70, 7070-7077. [CrossRef]

64. Calteau, A.; Fewer, D.P.; Latifi, A.; Coursin, T.; Laurent, T.; Jokela, J.; Kerfeld, C.A.; Sivonen, K.; Piel, J.; Gugger, M. Phylum-wide comparative genomics unravel the diversity of secondary metabolism in Cyanobacteria. BMC Genom. 2014, 15, 977. [CrossRef] [PubMed]

65. Miscoe, L.H.; Johansen, J.R.; Kociolek, J.P.; Lowe, R.L.; Vaccarino, M.A.; Pietrasiak, N.; Sherwood, A.R. The diatom flora and cyanobacteria from caves on Kauai, Hawaii. Acta Bot. Hung. 2016, 58, 3-4.

66. Zeng, J.; Zhan, J. Chlorinated Natural Products and Related Halogenases. ISR J. Chem. 2019, 59, 387-402. [CrossRef]

67. Härle, J.; Bechthold, A. Chapter 12 The Power of Glycosyltransferases to Generate Bioactive Natural Compounds. In Complex Enzymes in Microbial Natural Product Biosynthesis, 1st ed.; Hopwood, D.A., Ed.; Elsevier: Amsterdam, The Netherlands, 2009; pp. 309-333. ISBN 9780123745880.

68. Walter, J.M.; Coutinho, F.H.; Dutilh, B.E.; Thompson, F.; Thompson, C.C. Proposal of a new genome-based taxonomy for Cyanobacteria. PeerJ 2017. [CrossRef]

69. Salazar, V.W.; Tschoeke, D.A.; Swings, J.; Cosenza, C.A.; Mattoso, M.; Thompson, C.C.; Thompson, F.L. A new genomic taxonomy system for the Synechococcus collective. Environ. Microbiol. 2020, 22, 4557-4570. [CrossRef] [PubMed]

70. Sutcliffe, I.C.; Dijkshoorn, L.; Whitman, W.B.; on Behalf of the ICSP Executive Board. Minutes of the International Committee on Systematics of Prokaryotes online discussion on the proposed use of gene sequences as type for naming of prokaryotes, and outcome of vote. Int. J. Syst. Evol. Microbiol. 2020, 70, 4416-4417. [CrossRef] [PubMed]

71. Hugenholtz, P.; Chuvochina, M.; Oren, A.; Parks, D.H.; Soo, R.M. Prokaryotic taxonomy and nomenclature in the age of big sequence data. ISME J. 2021, 15, 1879-1892. [CrossRef] [PubMed] 